To the Editor:

\title{
Medullary carcinoma of the thyroid gland associated with Hashimoto's thyroiditis
}

We report a case of medullary carcinoma of the thyroid in a woman with Hashimoto's thyroiditis. The rate of occurrence of thyroid malignancies in patients with Hashimoto's thyroiditis ranges from $0.5 \%$ to $13 \%$ with an average of $7 \%$ [1]. The more commonly reported malignancies have been lymphoma [2] and papillary carcinoma [3]. There are only three previous reports of an association between diffuse Hashimoto's thyroiditis with histologically proven medullary carcinoma of the thyroid $[1,4,5]$.

A 52-year old woman presented with a solitary nodule in the right lobe of the thyroid of three weeks' duration. There was no family history of malignancies in the thyroid or other sites. Histology of the resected right thyroid lobe showed a medullary carcinoma composed of small uniform round cells arranged in sheets, cords, and trabeculae, with amyloid in the stroma (Figure 1). The non-neoplastic thyroid tissue and the left lobe which was removed 2 weeks later showed features of

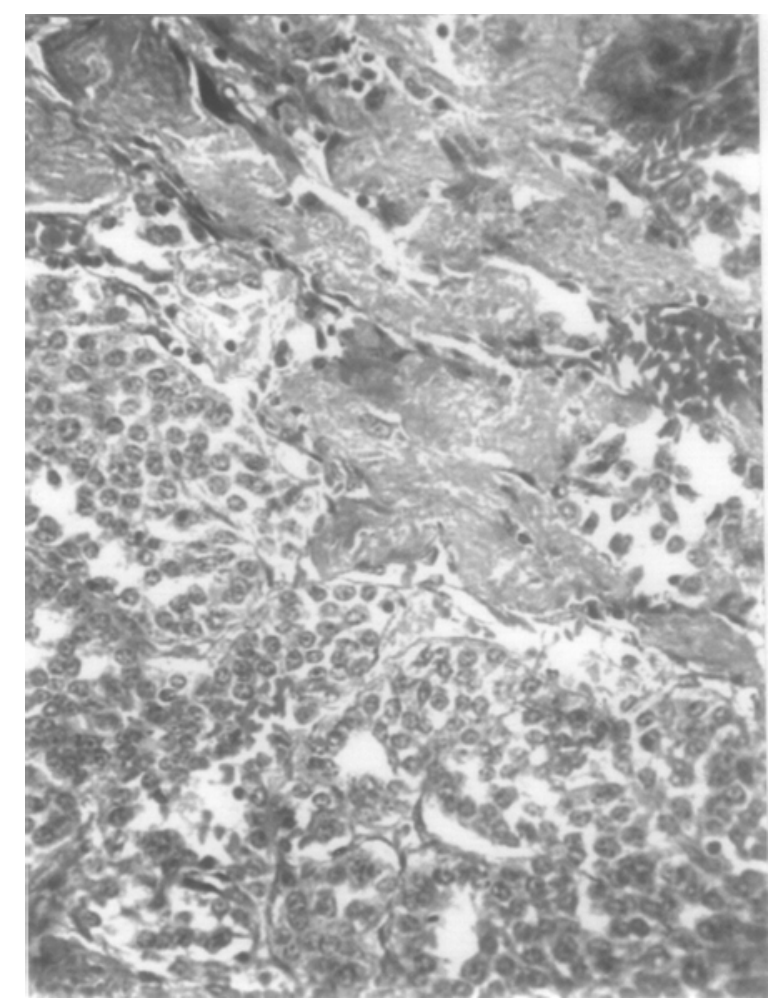

Figure 1. Medullary carcinoma: nests of tumour cells (left) with amorphous amyloid material (right) (H \& E X 100).
Hashimoto's thyroiditis, comprising fibrosis, destruction of acini, a dense lymphocytic infiltrate with lymphoid follicle formation and Hurthle cells (Askanazy cells). The patient had an uneventful recovery and remains well 6 years after surgery.

It has been suggested that prognosis of patients with carcinoma of thyroid gland with co-existing Hashimoto's disease is better than that of patients with carcinoma of the thyroid gland alone [5]. It would appear that thyroid carcinoma stimulates the development of Hashimoto's thyroiditis in some patients and that the autoimmune inflammatory reaction and the circulating antibodies retard the growth and dissemination of carcinoma of the thyroid gland [5].

Medullary carcinoma should be included in the differential diagnosis of carcinoma arising in association with Hashimoto's thyroiditis. Distinction of this entity from other types of thyroid carcinomas is necessary not only for treatment and assessment of prognosis, but also because such patients and their family members need to be screened for multiple-endocrine neoplasia syndrome.

\section{References}

1. Weiss LM, Weinberg DS, Wharhol MJ. Medullary carcinoma arising in a thyroid with Hashimoto's disease. American Journal of Clinical Pathology 1983; 80: 534-8.

2. Holm LE, Blomgren H, Lowhagen T. Cancer risks in patients with chronic lymphocytic thyroiditis. New England Journal of Medicine 1985; 312: 601-4.

3. Ott RA, Calandra DB, McCall A, Shah KH, Lawrence AM, Paloyan E. The incidence of thyroid carcinoma in patients with Hashimoto's thyroiditis and solitary cold nodules. Surgery 1985; 98: 1202-6.

4. Gaskin D, Parai SK, Parai MR. Hashimoto's thyroiditis with medullary carcinoma. Canadian Journal of Surgery 1992; 35: 528-30.

5. Segal K, Ben-Bassat M, Avraham A, Har-EI G, Sidi J. Hashimoto's thyroiditis and carcinoma of the thyroid gland. Surgery International 1985; 70: 205-9.

MAM Wijayawardena, HDP Gunawardane, Demonstrators, Department of Pathology, AH Sheriffdeen, Professor, Department of Surgery and MVC de Silva, Professor, Department of Pathology, Faculty of Medicine, Colombo. Correspondence: MVC de S, Tel: + 94112645 575, e-mail: <chandudesilva@yahoo.co.uk.>(Competing interests: none declared). Received 31 March 2004 and accepted 20 April 2004. 